\title{
Uncertainty with friction parameters and impact on risk analysis
}

\author{
T.D.M. Willis ${ }^{1,3, a}$ N.G. Wright ${ }^{2}$ P.A. Sleigh ${ }^{1}$ \\ ${ }^{1}$ School of Civil Engineering University of Leeds \\ ${ }^{2}$ School of Technology University of De Montfort \\ ${ }^{3}$ JBA Risk Management, South Barn Skipton
}

\begin{abstract}
Flood modelling is an essential component of risk analysis, with a greater demand for accurate and robust modelling to be undertaken at large spatial scales. Understanding of uncertainty in the modelling becomes increasingly critical not only in ensuring model results are reliable, but also in a wider context of (re)insurance regulations such as Solvency II. This research investigates how the uncertainty in the friction parameter impacts on model outputs and how this parameter influences uncertainty associated with evaluations of exposure (the estimation of damage caused by flood waters), and with evaluation of hydraulic outputs, including water depths and extents. Two basic approaches are adopted to representing friction values in a model; a uniform manning's $n$ value, and spatially distributed values based on underlying land type surfaces, and the use of appropriate friction values in these surfaces. The range of friction values in both approaches is based on literature values and are designed to represent the values typically used in modelling exercises, assuming a uniform distribution for this range.
\end{abstract}

\begin{abstract}
This uncertainty is also analysed in a wider Monte Carlo method, comparing other sources of uncertainty in flood modelling, including hydrological input uncertainty, DTM uncertainty and the uncertainty associated with the computational model used. 3 test cases, with different hydraulic properties are used to provide generic conclusions to the test cases. Two urban test cases with transcritical flow conditions and a river overtopping event in a rural/urban domain. The results from the model results are analysed with typical modelling evaluation techniques, such as binary flood extent comparison and depths comparison measures, as well as measures of exposure, here defined as the cost of damage associated with modelled water depths. The results demonstrate that modelling uncertainty is reduced by increasing the number of frictional surfaces in the modelling, indicating that through marginal pre-processing effort better representation of microscale hydraulics can be achieved, particularly in urban areas. Model results are also far more sensitive to uniform values, which also demonstrate an increased level of uncertainty, even in large scale modelling. The uncertainty associated with friction values though is shown to be relatively small compared to the uncertainty of the numerical scheme, and also displays significant parameter interaction.
\end{abstract}

\section{Introduction}

Flood inundation modelling forms a critical risk analysis tool. There is an increasing need and ability to understand risk across regions in terms of frequency of occurrence of flood events, through detailed flood hazard maps. The increase in demand for this data coupled with critical legislation that will force end users to understand the limitations of datasets, places uncertainty of flood models in greater importance for both decision makers and model developers. Uncertainty analysis has become critical in hydraulic modelling in recent years, with many studies exploring how different parameters contribute to it including hydrology (Di Baldassarre et al 2012), friction parameters (Hunter et al 2008), terrain data (Taskuabi et al 2013, Albiy et al 2015). In order to the contributions of these uncertainties, increasingly detailed analytical techniques are employed to evaluate how components of a model contribute to uncertainty including sensitivity analysis, (Hall et al 2005, and Pappenberger et al 2008, Albiy et al 2015), and screening methods (Willis et al in review).

While it is important to note how uncertainty effects the direct model output (depths and extents), it is also critical to note how these uncertainties filter through to evaluations of risk (Sampson et al 2014). The link between uncertainty in the flood inundation model and the risk is not always monotonic (Willis et al in review), and the precise nature of how uncertainty at one level of analysis will affect the overall evaluation of risk must be explored in more detail.

The advancement of 2D methods and datasets have allowed hazard mapping to become more accessible as a means of identifying flood risk, and allowed the development of broad scale mapping to be undertaken at global scale (Sampson et al 2015). In order to undertake this scale of mapping a number of broad assumptions about model inputs needs to be made, such as the hydrological model used to derive river discharge

$\overline{{ }^{a} \text { Corresponding author: thomas.willis@jbarisk.com }}$ 
in non-gauged locations and the friction value. The later input has often be used as an effective parameters, i.e. an input which is calibrated in order to overcome deficiencies in the model and under representation of hydraulic processes in the computer code. The precise nature of the application of the friction value can vary depending on the level of detail required from the model. Uniform friction values, where a single value is used across the entire domain are often used for their simplicity, and in the absence of detailed land surface information (Bates et al 2000). Spatially varied values allow some of the A typical approach to applying will be to split the friction value between the floodplain and the channel. This helps to improve the ability of the model to correctly depict channel conveyance. Where a 1D model is used, the detail can be extended to account for friction losses in the channel/floodplain boundary, and to account for variable channel bed material. Depth varied values also represent a detailed approach to considering friction losses. This approach attempts to capture the temporal variation of bed friction during a flood event, where the friction value will reduce through the event. This is particularly true in vegetated regions, where the volume of water associated with a flood wave propagating through the system will reduce the vegetative structure and reduce energy losses. The issue with applying this method is the level of certainty of the evolution of the friction slope and the lack of observed validation data.

This research explores how the value and application of the friction parameter, which is typically considered the primary source of uncertainty, and the focus of calibration efforts, influences evaluations of risk. Here the emphasis is not just on the direct model output, such as depths and extents, but also further evaluations of risk, in this case economic damage. In order to explore how significant this is as a source of uncertainty it is compared to other key flood model inputs, including model cell size and hydrology. It also compares the influence of the level of physical representation as a source of uncertainty. This allows two important insights to be gained. First, how significant is the application of the friction parameter in the model compared to the complexity of the physics model and secondly how does that change as the level of physical representation and the complexity of the numerical model change. The main variation of application of this value is based on a spatially distributed approach based on underlying land surface against a uniform value.

\section{Methodology}

Two test cases are explored here, with differing underlying hydraulic processes occurring in the floods events, which will provide a broad overview to how the application of friction parameters in the model affect. The systematic analysis is based on dividing each input factor into discrete levels, which represents choices that may be made by a modeller rather than based on a probability distribution of the input which may be based on broad assumptions. This is summarised in table one.

\begin{tabular}{|c|c|c|c|c|c|}
\hline $\begin{array}{c}\text { Parameter } \\
\text { Type }\end{array}$ & Range & \multicolumn{3}{|c|}{ Levels } & Notes \\
\hline Cell Size & $\begin{array}{l}2 \mathrm{~m}-4 \mathrm{~m} \\
\text { for urban } \\
\text { tests, } \\
20 \mathrm{~m}-40 \mathrm{~m}\end{array}$ & \multicolumn{3}{|c|}{2 levels } & $\begin{array}{c}\text { Based } \\
\text { on work } \\
\text { by } \\
\text { Fewtrell } \\
\text { et al } \\
(2008)\end{array}$ \\
\hline Hydrograph & $\begin{array}{c}20 \% \text { of } \\
\text { calculated } \\
\text { hydrograp } \\
\text { h }\end{array}$ & \multicolumn{3}{|c|}{$\begin{array}{c}5 \text { levels } \\
(-20 \%,- \\
10 \%, 0,+10 \%,+20 \%)\end{array}$} & $\begin{array}{c}\text { Value } \\
\text { based on } \\
\text { Di } \\
\text { Baldassa } \\
\text { rre et al } \\
\text { (2012) }\end{array}$ \\
\hline DEM error & $\begin{array}{l}0 \mathrm{~cm} \mathrm{-} \\
15 \mathrm{~cm}\end{array}$ & \multicolumn{3}{|c|}{$\begin{array}{c}2 \text { levels - } \\
\text { Original surface and } \\
15 \mathrm{~cm} \text { degraded }\end{array}$} & $\begin{array}{l}\text { LiDAR } \\
\text { vertical } \\
\text { RMSE }\end{array}$ \\
\hline $\begin{array}{c}\text { Building } \\
\text { Representati } \\
\text { on }\end{array}$ & $\begin{array}{c}\mathrm{BR}, \mathrm{BP}, \\
\mathrm{BB}\end{array}$ & \multicolumn{3}{|c|}{3 levels } & $\begin{array}{c}\text { Based } \\
\text { on } \\
\text { Schubert } \\
\text { and } \\
\text { Sanders } \\
(2012)\end{array}$ \\
\hline \multirow{15}{*}{$\begin{array}{l}\text { Friction } \\
\text { Value }\end{array}$} & & & Low & High & \multirow{15}{*}{$\begin{array}{l}\text { Mannin } \\
\text { g's } n \text { for } \\
\text { low } \\
\text { friction } \\
\text { Mannin } \\
\text { g's } n \text { for } \\
\text { high } \\
\text { friction } \\
\text { Uniform } \\
\text { friction } \\
\text { values }\end{array}$} \\
\hline & & 1. & $\begin{array}{c}0.00 \\
8\end{array}$ & 0.015 & \\
\hline & & 2. & $\begin{array}{c}0.00 \\
9\end{array}$ & 0.02 & \\
\hline & $\begin{array}{l}\text { Low } \\
\text { Friction - }\end{array}$ & 3. & $\begin{array}{c}0.01 \\
0\end{array}$ & 0.025 & \\
\hline & $\begin{array}{c}0.008- \\
0.020(13\end{array}$ & 4. & $\begin{array}{c}0.01 \\
1\end{array}$ & 0.03 & \\
\hline & $\begin{array}{c}0.01 \\
\text { difference }\end{array}$ & 5. & $\begin{array}{c}0.01 \\
2\end{array}$ & 0.035 & \\
\hline & ) & 6. & $\begin{array}{c}0.01 \\
3\end{array}$ & 0.04 & \\
\hline & $\begin{array}{l}\text { High } \\
\text { Friction }\end{array}$ & 7. & $\begin{array}{c}0.01 \\
4\end{array}$ & 0.045 & \\
\hline & & 8. & $\begin{array}{c}0.01 \\
5\end{array}$ & 0.05 & \\
\hline & $\begin{array}{c}\text { levels at } \\
0.05\end{array}$ & 9. & $\begin{array}{c}0.01 \\
6\end{array}$ & 0.055 & \\
\hline & ) & 10 & $\begin{array}{c}0.01 \\
7\end{array}$ & 0.06 & \\
\hline & & 11 & $\begin{array}{c}0.01 \\
8\end{array}$ & 0.065 & \\
\hline & & 12 & $\begin{array}{c}0.01 \\
9\end{array}$ & 0.07 & \\
\hline & & 13 & 0.02 & 0.075 & \\
\hline & $\begin{array}{c}\text { Single } \\
\text { Value } \\
0.01-0.07\end{array}$ & \multicolumn{3}{|c|}{$\begin{array}{l}7 \text { Levels for a } \\
\text { uniform friction } \\
\text { value surface. }\end{array}$} & \\
\hline
\end{tabular}

Table 1. Parameter type, range and levels for the systematic assessment.

In order to explore the uncertainty in the application of the friction parameter, two approaches are looked at a single uniform value and a spatially distributed value based on OS landform. A range of appropriate values are then picked for the underlying land surfaces identified in the OS data, to represent. Here, the spatial 
distribution of friction value is based on dividing the land coverage into two categories, low and high friction surfaces, with roads and tarmacked paths representing the low friction surfaces. Whilst this is a small category division, it will allow the influence of roads, which have a strong control on the development of flow pathways in urban flooding, to be established.

Each model output was then used to derive a total damage estimate for the event. This was achieved by using cells located in the perimeter of a building and appropriate depth damage curves from the Multi Coloured Manual (Penning Rowsell et al 2013) to determine a cost of damage value as a model output. By comparing across the model input ensemble and by cross comparing the application of the friction value, a comment about the effective of this model setup on risk analysis can be achieved.

\section{LISFLOOD-FP}

In order to use level of physical representation as an uncertain parameter, a modelling framework is required that ensures that the computer code setup is consistent between different physical models. This allows the impact of the different physics solutions to floodplain flow to be assessed. The LISFLOOD-FP code (Bates and De Roo 2000) has a number of different solutions to floodplain friction flow, with differing level of physical representation that have been validated in other studies. The model is a $2 \mathrm{D}$ regular grid model, with the cell centroid providing the DEM elevation used in the free surface calculation. Each floodplain module is based on a certain number of terms from the governing equations (Equation 1), each of which represent a flood wave with different physical attributes. Simplified and full physics solutions are provided in the framework which allows the level of physical representation to be considered as an uncertain input.

$$
\begin{aligned}
& \frac{1}{A} \frac{\partial}{\partial x}\left(\frac{Q^{2}}{A}\right)+\frac{1}{A} \frac{\partial Q}{\partial t}+g \frac{\partial y}{\partial x}-g\left(S_{o}-S_{f}\right)=0 \\
& \text { Convective Local Pressure Gravity Friction } \\
& \text { Acceleration acceleration term Force term Source Source }
\end{aligned}
$$

The lowest level of physical representation for solving the floodplain flow is the ATS module which represents an analytical solution to the diffusion flood wave. In this module, the intercell flux is estimated using the Manning's formula. Consequently momentum is not conserved, and floodwave movement is described in terms of bedslope difference and friction slope. This will capture the dominant processes in the floodplain (Thingy MAST)

In order to produce a stable solution to the diffusion wave problem, a time stepping method based on the
Von Neumann analysis of diffusion wave system was developed. The timestep is based on a quadratic of the cell size, which for detailed modelling with complex bathymetry, such as urban flood modelling, would lead to high computational costs (Hunter et al 2005).

\subsection{LISFLOOD-ACC}

In order to overcome the computational costs of the ATS module, a second simplified approach was developed, which would allow the CFL condition to be applied at the time step, thus allowing a less stringent condition to be applied, and increase the computational efficiency of the code (Bates et al 2010). The numerical model is created from a modified version of the momentum component of the governing equations, where the convective term is excluded from the model. A semi implicit, cell centred method is used to discretise the equation (de Almedia et al 2012), with a numerical diffusion parameter included to allow the model to remain stable at low friction values. This formulation appears to show a significant variation from the simplified diffusion wave approach (Neal et al 2012). Consequently this model represents an intermediate level of physical representation.

\subsection{LISFLOOD-Godunov}

The full shallow water equations are solved in LISFLOOD through a module which uses the Godunov method as the basis for the floodplain solver. This formulation solves local Reimann problems at the intercell flux to update conserved variables in cell centres. The Godunov method requires a Reimann solver to evaluate the intercell flux. Here two options are presented at varying levels of complexity, the Roe and Rusanov solver. Thus it is possible to comment on not only the level of physical representation of the solver, but also how critical the complexity of the methods used to solve the full SWE maybe on model results.

The Roe solver solves the full SWE (equation 2), and uses a linear approximation to the Jacobian matrix to solve the Reimann problem. The final term of the left hand side of the equation represents advection forces and is not present in the LISFLOOD acceleration module. This approach has been applied to a storage cell method previously (Villanueva and Wright, 2006). This method has been shown to provide a robust solution to the SWE's as well as providing a greater representation of floodplain hydraulic processes (Neal et al 2011). The Rusanov solver represents the lowest level of upwinding in a Godunov method. (Toro et al 2001). Whereas the Roe solver uses information from the local eigenvalue structure, the Rusnov solver uses the largest local wave speed to representing a bounding limit on the formulation. This information comes at a low computational cost, as this information is available 
in determining the time step for automated time step methods. This method has been shown to induce excessive smearing where discontinuities are strong but acceptable where the problem being solved is of a large scale, such as flood inundation problems (Simoes et al 2012).

\section{Results - Coventry}

The Coventry test case is based on a historic canal embankment failure, which occurred in December 1978 and led to the rapid outflow of the canal waters. A $1 \mathrm{~km}$ section of central Coventry was inundated by the waters, a region which included a number of residential units and industrial units, whilst a hospital The terrain data is a modified LiDAR dataset, using a resampled 2008 elevation model to create a surface model, and the 1978 urban topography data added to the elevation model to replicate the terrain and bathymetry for the event. The canal embankment outflow represents the inflow boundary conditions, which is calculated based on the methodology devised for the undertaking of the national scale flood risk assessment for canal bank failure (Dun and Wicks 2013).

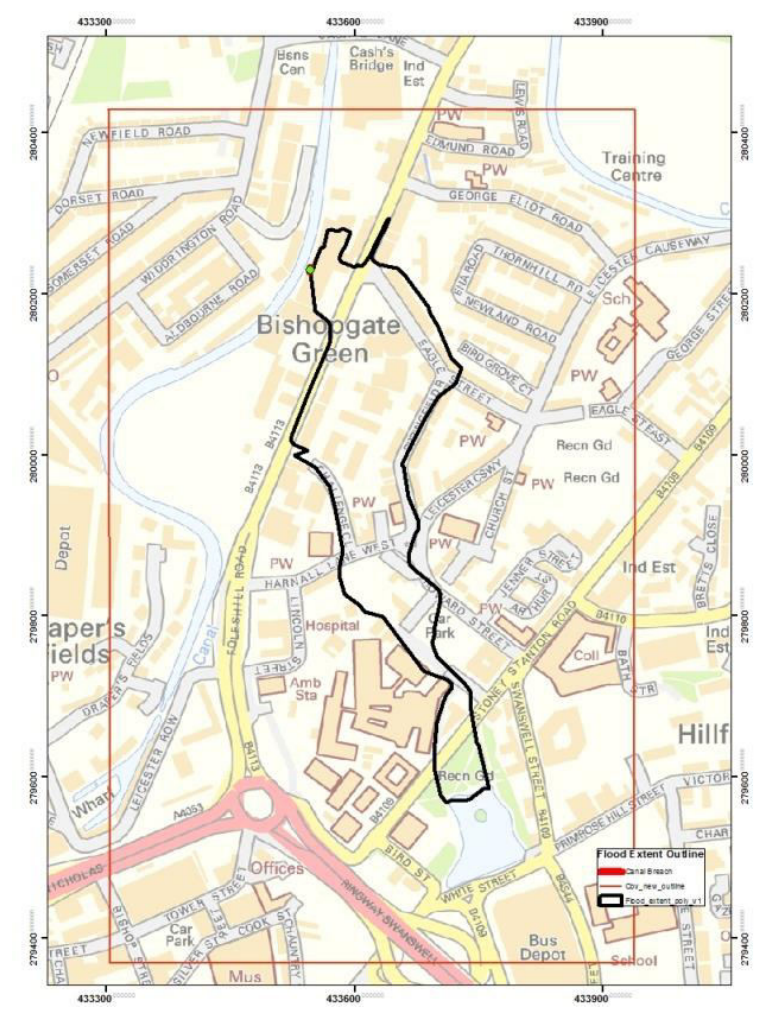

Figure 1. Outline of Coventry test case region and surveyed flood outline

The outflow which has a total inflow time of 2 hours with a peak of $21 \mathrm{~m} / \mathrm{s}$ occurring after 10 minutesm, is estimated from the volume of water available in a pound length of canal, the estimated time to complete failure of the bank, and the geometry and material of the bank. In the aftermath of the event a survey of the flood extent was undertaken (Figure 1). This allows the model results from the systematic approach to be evaluated, using the binary comparison extent method. Whilst this method has been noted for not necessarily allowing a model to be evaluated in terms of replicating complex hydraulic process, here this value is more appropriate, as replicating the flood extent will require some skill, rather than simple conserving mass in a domain where topographical features are a strong control on flood extents (Stephens et al 2012).

The results from the hydraulic model outputs indicate that where a low friction value is used to represent the roads, there is a marked difference in the arrival time and peak value of the flood wave. The distributed friction method, creates a flood wave that arrives earlier, with a lower peak, and a longer tail to the time series. This indicates that lower friction road surfaces, will produce a higher level of conveyance, with higher local velocities in the water. Whilst this only represents a local effect, the combined effect of this will lead to a

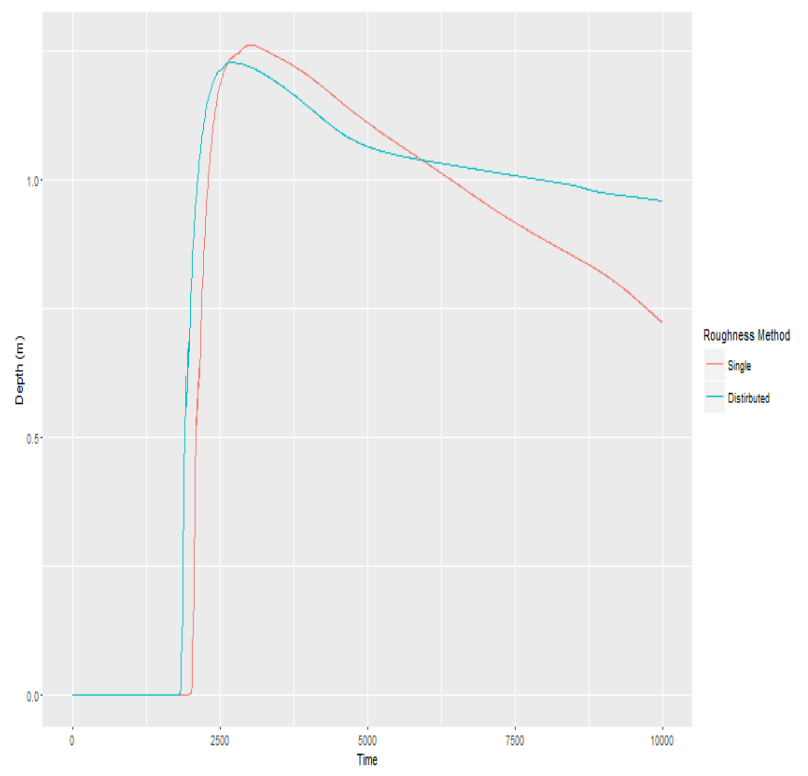

Figure 2. Comparison of depths, with varying friction application where is a uniform value and blue distributed value.

Analysis of the performance of the two friction application methods is summarised in Table 2 The range of results present indicate that the distributed friction method has a lower range, a higher peak value and higher mean value. This can also be seen in the boxplot figure (Figure 3). This indicates that the use of distributed friction surfaces reduces the sensitivity of the result to the precise value. This theoretically makes the models more robust - the approach of distributing the friction value by surface captures hydraulic processes. Either approach though, still produce a reasonable range of results and still indicates that a 
robust validation process is required to justify model input parameters.

\begin{tabular}{|l|l|l|l|l|l|l|}
\hline Method & Min & $1^{\text {st }} \mathrm{Q}$ & Median & Mean & $3^{\text {rd }} \mathrm{Q}$ & Max \\
\hline Uniform & 0.332 & $\begin{array}{l}0.57 \\
2\end{array}$ & 0.599 & 0.592 & 0.623 & 0.689 \\
\hline Distributed & 0.402 & $\begin{array}{l}0.58 \\
7\end{array}$ & 0.622 & 0.612 & 0.646 & 0.711 \\
\hline
\end{tabular}

Table 2. Summary of the F2 results for the Coventry test case

In the absence of data with which to validate the cost of damage it is difficult to determine the accuracy of the estimation of damage. However what can be seen in figure is a reduction in the range of results where a distributed friction surface is used (Figure 4)

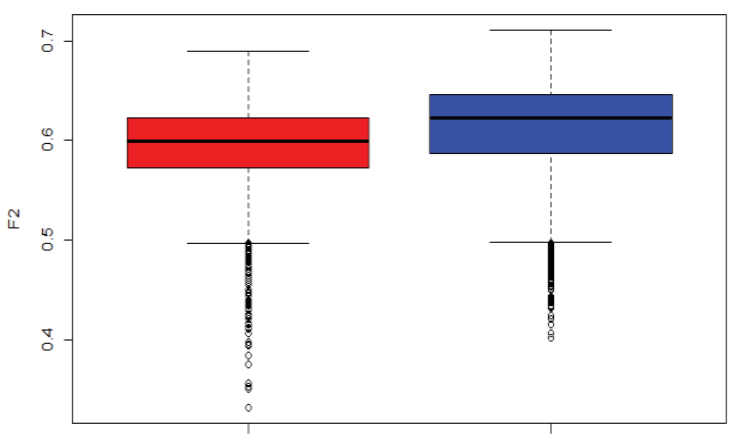

Friction

Figure 3. Boxplot of F2 results for Coventry test case for single friction value (red) and distributed friction (blue)

The distributed friction value produces a narrower range of estimate damages, as a result of enhancing the hydraulics down the road and transportation network. This allows the majority of water to be channelled through the model domain, in a manner consistent with the observed event. The channelling of this volume through the domain will also reduce the total volume available to the domain, ensuring that the depths of the water are similar across each model run. The single value produces a wide range of potential cost of damage for the event. The difference in range of values between the two approaches indicates that parameter interaction is a critical issue in determining how uncertainty of input parameters affects output. If the range was similar between the two friction distribution approaches, albeit offset, this would indicate that the combined uncertainties of the other parameters were influencing the model output. This suggests that uniform friction value will not only introduce uncertainty through the increased sensitivity of the output to the single value chosen, it will also enhance the uncertainty of other inputs. By comparison, the narrower range of results associated with, indicates not only that the level of uncertainty is reduced, it also indicates that the precise Manning's $n$ value used is less critical than if a uniform value is chosen. This has a clear advantage in risk analysis work, as reducing the sensitivity of a model input can potentially allow uncertainty in other components to be explored in greater detail. It should be noted though that the upper cost of damage value is the same for both friction distribution types. This demonstrates that regardless of the level of uncertainty for each approach a careful calibration process could overcome this to create a robust output from the modelling.

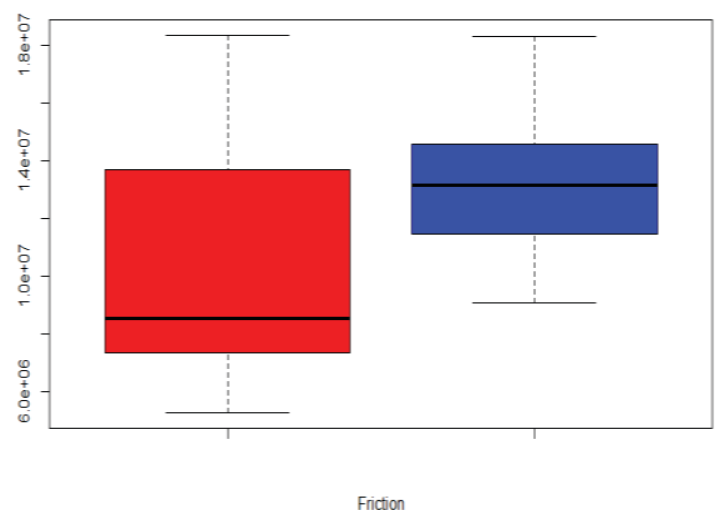

Figure 4. Boxplot of Cost of Damage results for Coventry test case for single friction value (red) and distributed friction (blue)

As the cost of damage analysis, there is a level of parameter interaction that occurs across the input ensemble that effect output. In order to explore this in more detail, interaction plots compare the significance of a parameter by calculating the mean value of a given level of an input compared to a level of another parameter. Previous work has indicated that the level of physical representation is of greater significance than the friction value (Willis et al in review). Figure 5 demonstrates the difference in mean F2 values for the different friction distribution approaches.

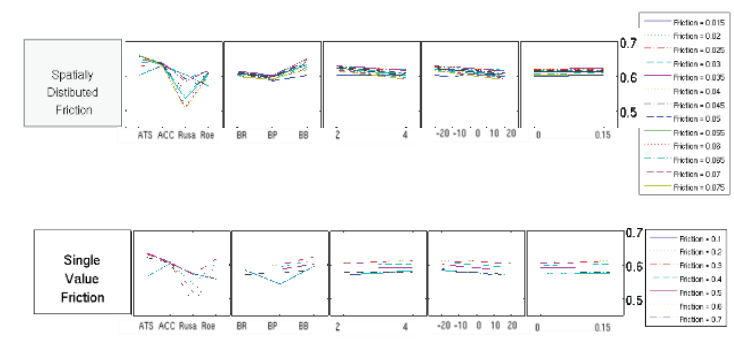

Figure 5 Comparison of mean level per parameter for spatially distributed friction (top) and single value friction (bottom). The comparison parameter from left to right is model type, building type, cell size, hydrograph, and DEM error

Figure 5 shows that there is a greater variation over the different levels of the physical representation, this can be seen by the variation of the line in the right hand side column, which represents the interaction between the 
level of physical representation and different physics levels. What can also be seen is similar output to that indicated in the analysis of the cost of damage there is a clear increase in the range of results in the single friction value, although the interaction remains the same for each parameter. Generally though, it can be seen that asides from the numerical model, the other parameters have low control on the overall flood extent.

\section{Results - Mexborough}

The Mexborough case study 2007 UK summer flood events were an extensive set of fluvial and pluvial flood events that lead to over $£ 3$ billion of damage. This test case is based on a fluvial flood event, where the floodplain hydraulics, dominated by diffusion wave processes are more critical, in comparison with the Coventry test case where local acceleration forces will be significant. A small adjustment to the basic setup outlined in the methodology section, is the increase of the cell size of the test case from 2 to $4 \mathrm{~m}$ to $20-40 \mathrm{~m}$, to account for the increase in model domain size. The model domain is outlined in Figure 6. A series of wrack marks were evaluated post event to allow for model validation, using the F2 method, and the hydrology estimated from a previous study (Leedal et al 2010) is used as the model input. The area is predominantly rural, although there are significant urban areas in the model domain. As such the transportation network dominates less of the model domain than in the previous test case.

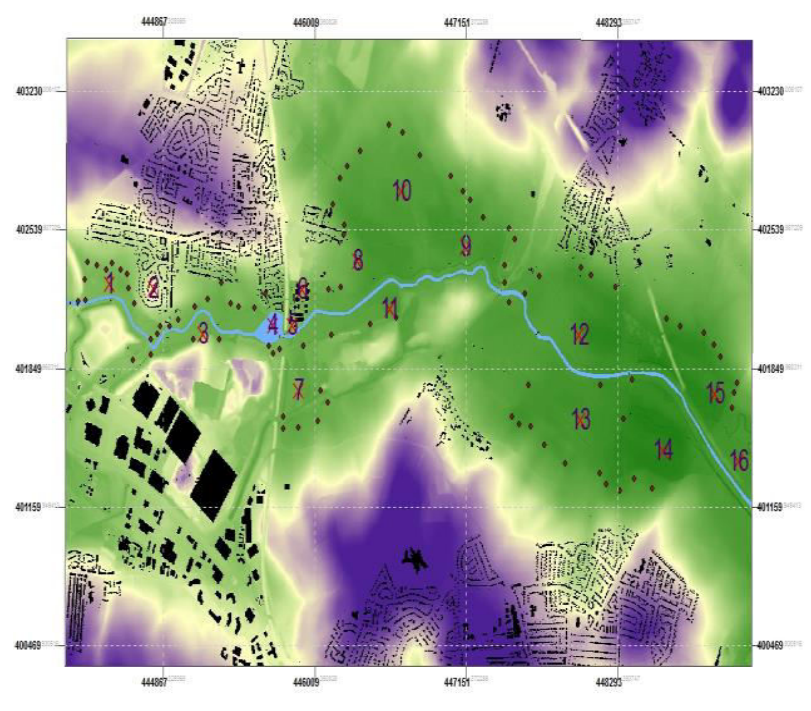

Figure 6. Model domain of Mexborough test case

A similar pattern is noted between the comparison of the objective function measure F2 that was observed in the Coventry test case, where the single value model setup creates a wider range of results (Figure 7). This is perhaps surprising considering how much smaller the transportation network is, and that the overall effect of representing this with different friction values would be reduced. Table 3 provides a statistical summary of the range of results from the model ensemble. A similar peak F2 value is recorded for both methods, indicating again that carfeul calibration will reduce the impact of these results.

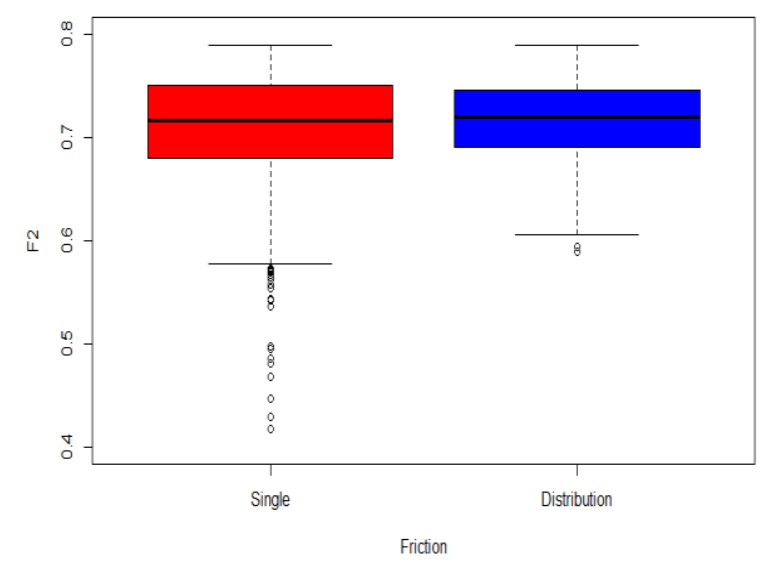

Figure 7. Boxplot of F2 results for Mexborough test case for single friction value (red) and distributed friction (blue)

\begin{tabular}{|l|l|l|l|l|l|l|}
\hline Method & Min & $1^{\text {st }} \mathrm{Q}$ & Median & Mean & $3^{\text {rd }}$ & Max \\
\hline Single & 0.417 & 0.680 & 0.716 & 0.708 & 0.750 & 0.789 \\
\hline Distributed & 0.589 & 0.690 & 0.720 & 0.714 & 0.746 & 0.789 \\
\hline
\end{tabular}

Table 3. Results summary for F2 values for Mexborough test case.

A similar pattern is also noted in the cost of damage as it is in the Coventry test case, where the range of results is greater for a uniform friction value. Here there effect appears to be smaller, as with the comparison of F2. A similar effect is noted, that the peak value of the two approaches are similar, indicating that a robust calibration process will ensure that either application is acceptable to overall model skill. The range of results for both the cost of damage and F2, are smaller than noted previously. Considering the relative size of the model domain and the fact that the transport network occupies less of the model domain, it is perhaps not as surprising to note. A conclusion can be drawn about the relative importance of the friction value depending on the underlying land type, and here is can be said that enhancing the transport network by reducing the friction value is of lesser importance than in urban flood modelling problems. 


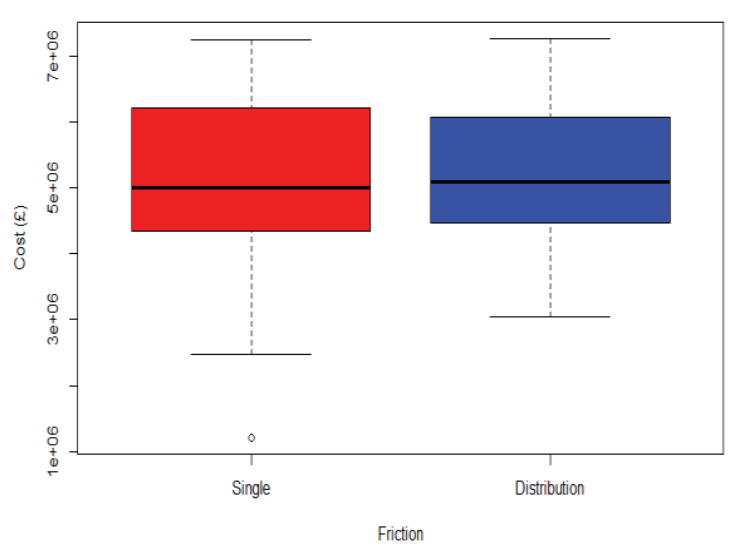

Figure 8. Boxplot of Cost of Damage results for Mexborough test case for single friction value (red) and distributed friction (blue)

Both approaches have produced a similar range of Cost of Damages, although a reduction in the minimal cost is noted with the distributed cost. As with the previous test case, there is no validation data, but the overall indication is that for this test case, where the model domain is rural and the hydraulics of the event are dominated by diffusion wave processes the need to represent detailed hydraulic processes, such as supercritical flow down roads, is less critical to the analysis of risk.

The impact of parameter interaction is reduced in this test case, as is the relative significance of each model input, as highlighted in the interaction plot of Figure 9 a similar effect of reduced range of mean F2 values can be seen, which again indicates that the introduction of spatially distributed values will reduce the overall mean values for the range of F2. What can also be seen is a change in the interaction of the model and friction parameter (cell 1) and the cell size and friction parameter (cell 3). This indicates that the different effects of the application will lead to other parameters becoming more significant, in this case the level of physical representation, as it introduces low friction surfaces where additional momentum terms become more significant, such as low flow, high velocity flow paths.
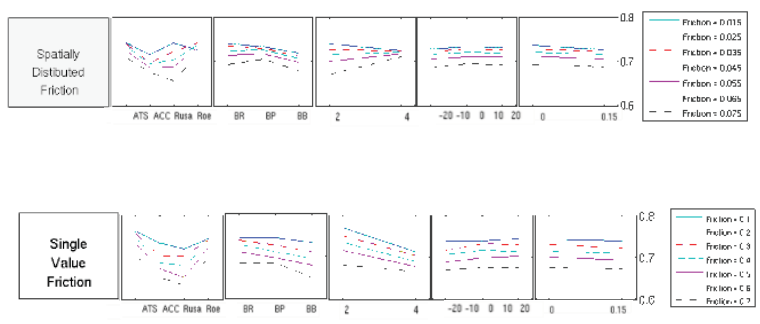

Figure 9 Comparison of mean level per parameter for spatially distributed friction (top) and single value friction (bottom). The comparison parameter from left to right is model type, building type, cell size, hydrograph, and DEM error
All models produce a reasonable result in terms of matching flood extent. This is in part related to the resolution of the model $(20-40 \mathrm{~m})$, which is coarse, even in scenarios where meso-scaled topographic features provide a greater control on model output than the precise combination of parameters. At this scale, the influence of the additional terms of the full SWE models compared to the simplified approaches of LISFLOOD-ACC and LISFLOOD-ATS are reduced. These additional terms are more significant in the solution of detailed, complex local flow situations such as flows around infrastructure. In this test case, however, this affect is minimal and is reflected in the similarity of the range. The application of spatially distributed parameters should be considered only significant in complex urban topographies.

\section{Discussions and Conclusions}

There is a clear reduction in the relative levels of uncertainty when using a distributed friction approach. The range of results across a similar size model ensemble reduces significantly for both F2 and Cost of Damage measures. This suggests 2 points. The first is that transport networks play a significant control on the propagation of a flood wave in urban areas. The development of critical flow paths, which will be controlled by low friction surfaces such as roads, needs to be represented in the model. The second point is that the relative values of friction chosen to represent the surface is less important than simply representing them. Single, uniform friction values will lead to an over reliance on the single friction value when considering the global model result, but also the effect of conveyance of flood waters down roads is poorly represented where a high friction value relative to the underlying surface.

In this research, the classic flood model objective function F2 has been used to evaluate model output. The relevance of this as a true measure of model skill and risk has been considered before (Stephens et al 2012), and this work highlights that comparison of extents are not a reasonable reflection of the variety of depths present across an uncertain model ensemble which is represented in the cost of damage measure. Here the relative range of F2 values is only $19 \%$ from maximum value to minimum. The evaluation of cost reveals a greater range of $49 \%$ relative, which indicates that depths vary far greater across the model ensemble than the extents do, and highlights the points made in previous research that suggests matching extent is a relatively easier objective. Whilst it has not been possible to validate the modelled damage, this variation does indicate that the use of F2 as a single measure of model ability is potentially flawed, and multi objective functions should be more robust in identifying a critical model structure (Dung et al 2010). 
The friction parameter is less significant as a contributor to output variance, than the effect of the choice of the numerical model. This can be seen in the interaction plots, where the mean function value varies far more over the different floodplain solutions than it does for the individual friction values. It should be noted then that in risk analysis, the solution of the numerical model should be considered before undertaking adjustments to parameter inputs. This follows a tendency to be over reliant on adjusting friction to overcome deficiencies in the modelling, leading to the use of effective parameters rather than physical relevant values.

This research indicates that a considered application of the friction parameter can reduce uncertainty and model performance. Here, only a two layered surface is considered the application of spatially distributed friction parameter. Further research is required in order to determine if the further division of this produces better results, or moves towards model equifinality. It also to be determined how each value relates to the range of uncertainty, and if one value can be fixed with limited effect on input. In order to determine this each level of input for both surfaces would need to be cross compared.

\section{References}

1. Abily, M., Bertand, N., Delestre, O.,Gourbesville, P., Duluc, C-M. Spatial Global Sensitivity Analysis of High Resolution Classiifed Topographic Data Use in 2D urban flood modelling Environmental Modelling \& Software In Review

2. Bates, P. D. \& De Roo, A. P. J. (2000). A simple raster-based model for flood inundation simulation. Journal of Hydrology, 236, 54-77.

3. Bates, P. D., Horritt, M. S. \& Fewtrell, T. J. (2010). A simple inertial formulation of the shallow water equations for efficient twodimensional flood inundation modelling. Journal of Hydrology, 387, 33-45.

4. Brandimarte, L. \& Woldeyes, M. K. (2013) Uncertainty in the estimation of backwater effects at bridge crossings. Hydrological Processes, 27, 1292-1300.

5. De Almeida, G. A. M., Bates, P., Freer, J. E. \& Souvignet, M. (2012) Improving the stability of a simple formulation of the shallow water equations for 2-D flood modelling. Water Resources Research, 48.

6. Di Baldassarre, G., Laio, F. \& Montanari, A. 2009. Design flood estimation using model selection criteria. Physics and Chemistry of the Earth, 34, 606-611.

7. Dung, N. V., Merz, B., Bardossy, A., Thang, T. D. \& Apel, H. 2011. Multi-objective automatic calibration of hydrodynamic models utilizing inundation maps and gauge data.
Hydrology and Earth System Sciences, 15, 1339-1354.

8. Fewtrell, T. J., Bates, P. D., Horritt, M. \& Hunter, N. M. 2008. Evaluating the effect of scale in flood inundation modelling in urban environments. Hydrological Processes, 22, 5107-5118.

9. Hall, J. W., Tarantola, S., Bates, P. D. \& Horritt, M. S. 2005. Distributed sensitivity analysis of flood inundation model calibration. Journal of Hydraulic Engineering-Asce, 131, 117-126.

10. Hunter, N. M., Bates, P. D., Neelz, S., Pender, G., Villanueva, I., Wright, N. G., Liang, D., Falconer, R. A., Lin, B., Waller, S., Crossley, A. J. \& Mason, D. C. (2008) Benchmarking 2D hydraulic models for urban flooding. Proceedings of the Institution of Civil Engineers-Water Management, 161, 13-30.

11. Neal, J., Villanueva, I., Wright, N., Willis, T., Fewtrell, T. \& Bates, P. (2011) How much physical complexity is needed to model flood inundation? Hydrological Processes,

12. Sampson, C. C., Fewtrell, T. J., Duncan, A., Shaad, K., Horritt, M. S. \& Bates, P. D. 2012. Use of terrestrial laser scanning data to drive decimetric resolution urban inundation models. Advances in Water Resources, 41, 1-17.

13. Schubert, J. E. \& Sanders, B. F. 2012. Building treatments for urban flood inundation models and implications for predictive skill and modelling efficiency. Advances in Water Resources, 41, 49-64.

14. Simoes, F. J. M. (2011) Finite Volume Model for Two-Dimensional Shallow Environmental Flow. Journal of Hydraulic Engineering-Asce, 137, 173-182.

15. Stephens, E.M, Bates, P.D., Freer, J E, Mason, D.C The impact of uncertainty in satellite data on the assement of flood inundation models Journal of Hydrology, 414, 162 -173

16. Toro, E. F. 2001. Shock Capturing Methods For Free-Surface Shallow Flows, Wiley And Sons Ltd.

17. Tsubaki, R. \& Kawahara, Y. (2013) The uncertainty of local flow parameters during inundation flow over complex topographies with elevation errors. Journal of Hydrology, 486, 71-87.

18. Villanueva, I. \& Wright, N. G. (2006) Linking Riemann and storage cell models for flood prediction. Proceedings of the Institution of Civil Engineers-Water Management, 159, 2733. 